\title{
A ENUNCIAÇÃO EM UM SOPRO DE VIDA, DE CLARICE LISPECTOR
}

\author{
Leticia Pilger da Silva \\ Mestranda em Estudos Literários pela Universidade Federal do Paraná (UFPR) \\ leticiaspilger@gmail.com
}

RESUMO

Este artigo analisa a subjetividade, a heterogeneidade constitutiva da enunciação e o papel do leitor em Um sopro de vida, de Clarice Lispector, a partir da teoria da enunciação. Como resultado, compreende-se o sujeito como uma posição e propõe-se uma leitura matrioskal, pois o dêitico eu pode ser preenchido pelos personagens, por Clarice e pelo leitor, de modo que há uma heterogeneidade dêitica que culmina em uma equivocidade e abre o texto para a quarta dimensão da leitura e para a obliquação do leitor.

Palavras-chave: sujeito, enunciação, Clarice.

\section{ABSTRACT}

This paper analyzes the subjectivity, constitutive heterogeneity of the enunciation and the role of the reader in Um sopro de vida, by Clarice Lispector, under the light of the theory of enunciation. As a result, the subject is understood as a position and a matrioskal reading is proposed, for the deitic I may be filled by the characters, the writer, and the reader, generating a deictic heterogeneity that culminates in an equivocality, opening of the text to a fourth dimension of the reading process and to the obliquation of the reader.

Keywords: subject, enunciation, Clarice. 


\section{Introdução}

O ser humano é formado por uma heterogeneidade constitutiva: na cisão interna entre consciente e inconsciente; ou na discursividade, como eu referente e eu referido da enunciação, ocupando as posições reversíveis de sujeito e objeto no enunciado; ou na polifonia do dialogismo, pois um sujeito produz um enunciado que ecoa outros, de modo que todo ego é ecoante. Isto é, todo sujeito é vários. O que chamamos de sujeito é uma multiplicidade de posições pelas quais é possível transitar. A literatura, enquanto ficção, abre posições de sujeito e se configura como um espaço onde podemos experienciar esse trânsito por outros eus e dividirmo-nos em egos imaginários na escrita e na leitura. A palavra literária permite, então, que experimentemos outros modos de existência.

É essa experiência que Clarice Lispector traz ao primeiro plano em Um sopro de vida (SV), texto que, ao dramatizar a criação literária e a reversibilidade das posições enunciativas, joga com as divisões do sujeito literário - revelando o caráter deslocado e fragmentado da identidade do sujeito moderno, do autor que é também leitor, do autor que é personagem, do eu que é o outro - e propondo uma posição oblíqua entre o eu e o outro. Enquanto, em geral, no Ocidente, a cisão do sujeito é tida como dualismo hierárquico, isto é, eu vs outro, sujeito vs objeto, no texto de Clarice não há preponderância de um polo, mas tensionamento e coexistência dos polos. A partir disso, nosso objetivo é investigar a posição oblíqua construída dentro do livro, considerando o caráter metalinguístico do texto e a dramatização da criação literária no discurso literário por meio de uma torção ulterior das instâncias narrativas, a saber: escritor, autor, narrador, personagem e leitor, questionando: quem é que fala/escreve o livro? 


\section{Os sujeitos oblíquos}

O enredo de SV é diluído e se resume a um escritor não nomeado e identificado como "Autor" escrevendo no aqui e agora uma personagem chamada Ângela Pralini, que também é uma escritora e que, por sua vez, está escrevendo seu livro "História das coisas". O livro realiza, assim, um corpo-a-corpo com a língua, mostrando a não-existência da realidade posposta no texto para além de sua materialidade; e também faz a dramatização da criação literária por meio de uma cena enunciativa, de sua estrutura dialogada entre criador/autor e criatura/personagem, isto é, Autor e Ângela, de modo que o livro conta a escritura do Autor e do seu homo fictus, Ângela, o diálogo entre criação e obra, e a escritura de um livro dentro do livro.

Por meio da criação literária, Clarice e seus personagens multiplicam-se ao se dividirem (e vice-versa) e, com isso, rompem com os dualismos do pensamento ocidental, mostrando que os polos supostamente binários podem (con)fundir-se uns nos outros (o eu é o outro do outro), o feminino e o masculino se mesclam, o criador é criado pela criatura e a cria. Os sujeitos envolvidos no texto são, portanto, oblíquos uns em relação aos outros, mas eles não se (con)fundem de fato. Dessa forma, o texto forma equivocidade na relação eu-tu, que demanda a comunicação encenada no texto e a confusão da lógica que rege os dualismos.

O sopro da criação pulsa um texto dividido em quatro partes. Na primeira, espécie de prefácio, há um narrador masculino - posteriormente desdobrado em dois personagens: Autor e Ângela - que relata sua concepção de escrita e o motivo de ter criado Ângela. O narrador diz ter escrito esse relato inicial depois de ter lido o seu próprio livro, que é, nas palavras dele, uma espécie de ouroboro, sendo a leitura o morder do 
rabo da escritura: ele anuncia seu livro depois de transitar entre as posições de escritor, autor e, finalmente, leitor de si, fechando - ou reiniciando - o ciclo.

Na segunda e terceira partes, intituladas, respectivamente, "O sonho acordado é que é a realidade" e "Como tornar tudo um sonho acordado?", o narrador se desdobra nos dois personagens que realizam um diálogo-monólogo entre si, em uma dramatização do fluxo de consciência sobre a vida, a morte, as coisas, Deus e a criação literária. $\mathrm{Na}$ última, chamada "Livro de Ângela", há o livro da personagem criada ao longo do livro podemos dizer que todo o livro é uma preparação para isso, para o livro dentro do livro, o testemunho da criação da criação. O livro é, portanto, resultado de uma despersonalização, e culmina não na dessubjetivação ou na perda identitária, mas na multiplicidade.

Ao longo do texto, o narrador se constitui pelo outro, pelo processo de escrita e pela linguagem, que, amalgamados, fazem com que seu objetivo com a escrita do livro seja "salvar a vida de alguém. Provavelmente a minha própria" (LISPECTOR, 1978, p. 11). Além disso, segundo o narrador, o livro é "a sombra de mim" (ibid., p. 11), um duplo, um fragmento de si, desse "mim" que já é duplo da duplicação via palavra, pois, como diz, "A sombra de minha alma é o corpo. O corpo é a sombra de minha alma" (ibid., p. 11) reversão que desfaz a hierarquia do dualismo corpo e alma. Ele é corpo e alma, corpalma. Isso mostra a inversão do cogito ergo sum cartesiano: no lugar de "penso, logo existo", Clarice propõe "existo, logo penso" (PENNA, 2010), de modo que existir (n)o mundo precede pensar (sobre) o mundo.

Adiante, o narrador relata que, para ter a salvação, ele gostaria de escrever um livro e "prescindir de ser discursivo" e do "fato", vivendo na escrita, pois "o resultado fatal de eu viver é o ato de escrever", e, para ele, "escrever é uma indagação: É assim:?" 
(LISPECTOR, 1978, p. 13-15). Escrever é uma pergunta. Sem resposta. Para isso, ele precisa se colocar no vazio, abdicar-se do eu - que já é um dêitico - e dirigir-se para o impessoal da vida, na busca do que atravessa todos os seres, sem, contudo, criar unicidade:

será horrível demais querer se aproximar dentro de si mesmo do límpido eu? Sim, e é quando o eu passa a não existir mais, a não reivindicar nada, passa a fazer parte da árvore da vida - é isso que luto por alcançar. Esquecer-se de si mesmo e no entanto viver tão intensamente. [...] Para escrever tenho que me colocar no vazio (LISPECTOR, 1978, p. 15).

Para escrever seu livro e salvar-se, ele diz que vai criar uma personagem chamada Ângela Pralini. Ela - e a escrita - é criada de "destroços de livro" e "restos de uma demolição de alma" (ibid., p. 19), que advém da multiplicação e da invenção-descoberta de uma realidade outra possibilitada pela criação ficcional, ou, como o narrador diz: "[os fragmentos] são cortes laterais de uma realidade que se me foge continuamente" (ibid., p. 19). Essa realidade oblíqua, contudo, não é composta de fatos, mas de "rápidos vislumbres meus e rápidos vislumbres de meu personagem Ângela" (ibid., p. 19), em uma espécie de duplo diário feito de anotações e flashes do aqui e do agora sobre sensações e impressões de si e do mundo. O narrador quer, com as sensações duplas, conhecer-se e compreender a vida. Indaguemos então: por que, para isso, criar um personagem é tão importante? Por que ele teve que criar um personagem e não simplesmente falar de seus próprios vislumbres? Como o próprio narrador diz, o Autor cria Ângela pela existência de "leis que regem a comunicação" (ibid., p. 15) e a enunciação, que determinam a 
necessidade de um outro, um interlocutor para realizar um diálogo e poder transitar por entre as posições sujeito e objeto (FRIAS, 1998).

A enunciação é definida por Benveniste (1989) como um evento singular e irrepetível no qual a língua é colocada em ação e transformada em discurso, que demanda que o eu, o sujeito, o enunciador, diga algo - um enunciado - a alguém. Destarte, o dêitico sui-referencial eu "propõe outra pessoa, aquela que, sendo embora exterior a 'mim', torna-se o meu eco, ao que digo tu e me diz tu' (BENVENISTE, 1991, p. 286), de modo que o eu e o tu são posições reversíveis dentro do discurso, seja no enunciado ou na enunciação, e constroem um diálogo, uma comunicação.

Por conseguinte, ao escrever eu e tu, ao colocar-se no vazio da palavra escrita, o narrador abre a enunciação para os sujeitos envolvidos no evento literário se anunciarem e, desse modo, abre espaço para outros que não $e u$, que podem posicionar-se no dêitico e viver a literatura. Podemos, então, dizer que o narrador se desdobra em si mesmo, na forma do personagem Autor e em Ângela por uma necessidade enunciativa: precisamos de um outro com quem dialogar:

não é fácil lidar com Ângela, a mulher que inventei porque precisava de um fac-símile de diálogo. [...] Será que criei Ângela para ter um diálogo comigo mesmo? (LISPECTOR, 1978, p. 28-30).

O monólogo do Autor começa e é desdobrado em um diálogo com Ângela, que pode ser considerado um duplo monólogo de três "eus", Autor, Ângela e Clarice, pois, como o Autor fala "- Eu e Ângela somos o meu diálogo interior - eu converso comigo mesmo" (ibid., p. 65). Porém, temos a impressão de que não há um efetivo diálogo entre eles, pois ambos parecem falar para si próprios, embora suas falas estejam intercaladas 
na materialidade do texto. Como o próprio Autor fala, o diálogo entre ele e sua criatura é um "diálogo de mudos":

[AUTOR -] notei que meu diálogo com Ângela é diálogo de surdos: um diz uma coisa e o outro diz sim mas a coisa diversa, e venho eu dizendo não, e vejo Ângela nem sequer me contradizer. Cada um de nós segue o próprio fio da meada, sem ouvir muito o outro (LISPECTOR, 1978, p. 91).

Ao longo do texto, podemos até questionar se Ângela sabe da existência do Autor. Assim, por Ângela ser um desdobramento do Autor sem, contudo, fundir-se a ele, o diálogo entre ambos se configura como dois monólogos, forma de enunciação que, segundo Benveniste, é um diálogo interiorizado em que o eu se desdobra em referente e referido, em locutor e interlocutor, e ouve-se enunciar-se (BENVENISTE, 1989). Logo, a interlocução entre eles é um diálogo-a-um ou um monólogo-a-dois e pressupõe a enunciação, pois esta é resultado de um desdobramento que acarreta sobreposição dos dois sujeitos e faz com que o diálogo seja composto por apenas uma e várias vozes ao mesmo tempo, já que eles são desdobramentos um do outro e, ao conversarem entre si e consigo mesmos, ecoam-se, pois "não só quem diz eu é sempre outro, como também todo eu ecoa um outro. Ou melhor: outros. Pois, cada ego humano é também uma multiplicidade" (NODARI, 2015a, p. 27). Podemos ver uma prévia de uma encenação enunciativa de um diálogo internalizado no texto "Quem ela era":

- (Eu te amo)

- (É isso então o que sou?)

- (Você é o amor que eu tenho por você)

- (Sinto que vou me reconhecer... estou quase me vendo. Falta tão pouco)

- (Eu te amo) 
- (Ah, agora sim. Estou me vendo. Esta sou eu, então. Que retrato do corpo inteiro) (LISPECTOR, 1980, p. 55).

O travessão marca o início da fala, mas os parênteses escancaram o que está para além do dito: talvez atrás do silêncio, ou do pensamento? O diálogo entre parênteses se realiza sem palavras, mas em pensamento e através da poética do olhar: um alguém está reconhecendo-se ao se ver no espelho - "estou quase me vendo". Ou, considerando que a interlocução acontece entre parênteses, para além do dito, poderíamos pensar que o diálogo encenado na crônica é um monólogo de alguém com seu Outro no espelho? 0 diálogo só se realiza com a presença do outro, e este outro está presente na materialidade do enunciado: "eu te amo". Além disso, esse "eu" define o outro pela sua relação quando diz "você é o amor que eu tenho por você". Sujeito e objeto se (con)fundem. O breve diálogo acaba quando o primeiro enunciador, como Narciso, se vê e conclui quem é - "esta sou eu".

De forma similar, em SV há o texto secundário com um nome seguido de um travessão no início de cada fragmento marcando o enunciador (Autor ou Ângela). Além disso, há o espaço que separa as falas de ambos os personagens, uma espécie de entrelinha alongada que configura silêncio e intervalo subjetivo que os divide e os une, pois cada um se posiciona nos dêiticos quando o texto secundário anuncia-os. Cabe ao leitor ler as entrelinhas a fim de resolver a (con)fusão entre os dois personagens separando-os ou os diluindo - e construir coerência entre a disposição dos fragmentos.

Porém, percebemos rastros de um diálogo, que se mostra, na verdade, um eco, um adendo um do outro, uma continuidade diferente, como neste trecho em que as reticências das falas se ligam na leitura: 
[AUTOR-] Eu uso o homem e não o conheço. Eu me uso e...

ÂNGELA-... e vejo tudo com perspectivas novas (LISPECTOR, 1978, p. 93).

Em certos momentos em que o Autor toma a cena enunciativa, no meio de sua fala um travessão é colocado, como que sinalizando que até então ele estivesse comentando seu texto e, a partir daquele ponto, ele (tentasse) dialogar(sse) com Ângela ou abrisse um espaço para o diálogo efetivo, inserindo o outro pela marca gráfica:

[AUTOR -] Fora de mim sou Ângela. Dentro de mim sou anônimo. Viver exige tal audácia. Me sinto perdido como se estivesse dormindo no deserto do Ministério da Fazenda.

- Ângela, agora estou me dirigindo diretamente a você e peço-lhe pelo amor de Deus para você enfim chorar [...] (LISPECTOR, 1978, p. 44).

Não são sujeitos diferentes que falam, mas vozes e camadas que formam um mesmo sujeito, que, no entanto, não culmina na supremacia de um indivíduo uno, mas na sua clivagem e na importância do outro para a constituição da subjetividade. Como mencionamos, todo ego é um eco, pois todo enunciado carrega diversos outros enunciados ditos anteriormente pelo próprio enunciador e por outros - configurando uma polifonia. Logo, o locutor também é um receptor, pois não é o primeiro locutor, mas pressupõe a existência prévia do sistema linguístico e de enunciados anteriores, sejam estes ditos e/ou escritos por ele ou por outros (BAKHTIN, 1997), como o Autor mesmo diz: "Fui invadido pelas palavras dos outros" (LISPECTOR, 1978, p. 93).

Assim, poderíamos dizer, tomando a lente cultural como horizonte, que a interlocução é um monólogo-a- $\infty$, como diz o Autor: 
Eu, o autor deste livro, estou sendo tomado por mil demônios que escrevem dentro de mim. Essa necessidade de fluir, ah, jamais, jamais parar de fluir. Se parar essa fonte que em cada um de nós existe é horrível (LISPECTOR, 1978, p. 93).

É uma totalidade vocal que não exclui a subjetividade do enunciador. É uma primeira pessoa que é várias. Desse modo, temos uma unidade que porta em si uma infinitude, um indivíduo ecoado e perpassado por outros indivíduos na experiência verbal individual, que

[...] toma forma e evolui sob o efeito da interação contínua e permanente com os enunciados individuais do outro. É uma experiência que se pode, em certa medida, definir como um processo de assimilação, mais ou menos criativo, das palavras do outro (e não das palavras da língua). [...] nossos enunciados [...] estão repletos de palavras dos outros [que] introduzem sua própria expressividade, seu tom valorativo, que assimilamos, reestruturamos, modificamos (BAKHTIN, 1997, p. 313-14).

Além disso, outro fato concernente à enunciação é o tempo do texto, então perguntemos: qual o tempo do texto? O tempo dele é o tempo da enunciação, que é um acontecimento sempre presente, de modo que o enunciado é escrito no momento em que é concebido. Como é sempre presente, os tempos da história - que prescinde dos fatos - e do discurso são sobrepostos, de modo que a enunciação é o próprio tema dos vislumbres de Autor e Ângela. A sobreposição passado-presente-futuro faz com que enunciado e enunciação se confundam e as fases da enunciação literária - escritura e leitura - se misturem e causem a confusão das subjetividades, que deixam de ser sujeitos concretos e passam a ser posições e funções dentro da narrativa, de modo que a unidade ficcional de um in-divíduo é levada à multiplicidade. 


\section{Linguagem oblíqua}

Os personagens do livro reconhecem a si e à vida como oblíquos e enviesados, já que são habitantes de uma realidade outra:

[ÂNGELA-] Eu sou oblíqua [...]. Me espio de viés. (LISPECTOR, 1978, p. 40)

[AUTOR-] As coisas acontecem indiretamente. Elas vêm de lado. [...] Eu sou um abismo de mim mesmo. Mas sempre serei enviesado (ibid., p. 79-84).

Não só os sujeitos do texto são oblíquos, amalgamando-se e trocando de posição na enunciação; também o é a linguagem clariceana (NODARI, 2015b), que, ao nos sujeitar e permitir que nos subjetivemos, reflete a obliquidade dos sujeitos e as possibilidades de preenchimento do eu no texto sem haver univocidade. Sintaticamente redundante e importante semanticamente, a estrutura escancara a relação transladada entre os sujeitos do texto e o espelhamento entre sujeito e objeto das orações, isto é, que ocupa tanto a posição de sujeito quanto de objeto, num "inter-esse" (NODARI, 2015b, p. 149). Além da estrutura verbal, a organização dramática do texto e as entrelinhas da enunciação entre as falas de Autor e Ângela seriam espaços de obliquação ao permitirem que os sujeitos envolvidos no texto se obliquem.

A obliquação da linguagem revela a impossibilidade da separação entre os sujeitos dentro do enunciado e da enunciação e a criação de uma zona "tão volátil e quase inexistente que fica entre mim e eu" (LISPECTOR, 1998 p. 21), um terceiro espaço de trânsito de posições. Como resultado do ato de obliquar-se na linguagem, podemos recuperar este trecho em que G.H. fala que passa por uma "metamorfose de mim em mim mesma [...] em que perco tudo o que tinha, e o que eu tinha era eu" (LISPECTOR, 
2009, p. 66), que culminará no ato de responder toda vez que alguém falar "eu" de Lóri, revelando que o tu do "eu" enunciado por outro também é um eu ao se (a/e)nunciar. 0 dêitico é uma possibilidade enunciativa, não de quem fala, mas "do lugar de onde se fala, do mundo onde se fala", não "(mundo-para-um-sujeito)", mas um "(mundo-de-um sujeito)" (NODARI, 2015a, p. 19). A obliquação é uma experiência que permite multiplicidade e reconhecimento de um mundo que não o "meu", no qual o "eu" é Outro. Analisemos a frase (1), dita por Ângela, para desmembrarmos a obliquidade do texto:

Figura 1 - Análise da frase dita por Ângela

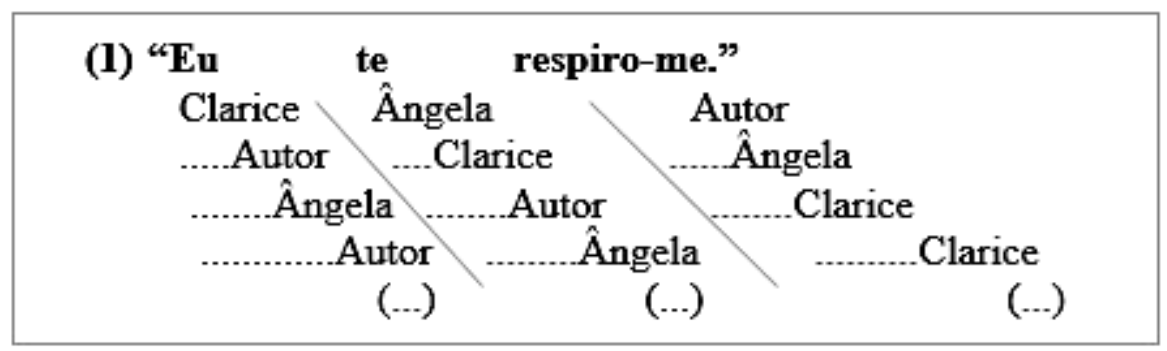

(LISPECTOR, 1978, p. 40)

$\mathrm{O}$ ato de respirar tem um sujeito, um eu, e um objeto na forma de pronome oblíquo átono te, isto é, um eu respira um te. Porém, por ter outro pronome oblíquo átono - me amalgamado ao verbo, há dois objetos respirados e, por isso, o te e o me são espelhados. O sujeito respira e é respirado ao respirar. Porém, ele necessita do outro para cumprir o ato de respirar, o te abre espaço para o me. Há duas possibilidades de paráfrase: (I) [Eu respiro você em mim] e (II) [Eu me respiro ao respirar você], que, juntas, resultariam em (III) [eu me respiro você em mim ao respirar você]. Apesar de tal sentença ser enunciada pelo Autor, considerando a obliquidade dos sujeitos do texto, podemos perguntar: quem respira quem? Quem é o eu, o te e o me? Como apontado, há diversas possibilidades de mundo enunciadas, que já mostram a variedade de mundos dentro de uma mesma frase. 
A cada possibilidade de $e u$, se considerarmos os três sujeitos escancarados no corpo do texto, há pelo menos duas (em uma infinidade de) possibilidades de obliquação. Uma única frase permite diversas perspectivas e cada preenchimento do dêitico eu e do seu interlocutor abre/encavalga/obliqua novas possibilidades e outros corpos, pois "não só quem diz eu é sempre outro, como também todo eu ecoa um outro. Ou melhor: outros. Pois, cada ego humano é também uma multiplicidade, um mundo: 'nosso' corpo é formado por (é a casa de) infinitos corpos alheios [...]" (NODARI, 2017, p. 16).

Além disso, na apresentação de Ângela, o Autor prefigura uma quarta dimensão no texto:

A ÚLTIMA PALAVRA será a quarta dimensão.

Comprimento: ela falando

Largura: atrás do pensamento

Profundidade: eu falando dela, dos fatos e sentimentos e de seu atrás do pensamento.

Eu preciso ser legível quase no escuro (LISPECTOR, 1978, p. 25).

Podemos pensar que o comprimento, quando Ângela está falando, seria o dito, o consciente; a largura seria o não-dito, o "atrás do pensamento", o inconsciente; e a profundidade seria o ato de narrar, de falar do dito, por meio da citação, e do não-dito, pela escrita. Por fim, a "última palavra" seria a quarta dimensão: que dimensão seria essa? Que palavra última seria essa?

Na física moderna, a partir da teoria da relatividade, o tempo é a quarta dimensão, considerando sua relação com a espacialidade, e também a duração e simultaneidade dos tempos (BERGSON, 2006). Tal tempo é relativo a um ponto de coordenadas, isto é, um ponto do espaço-tempo, e sua duração depende da percepção das pessoas. Ao considerar 
o tempo como quarta dimensão, a temporalidade do texto é o aqui e o agora. O texto é o ponto de coordenadas do espaço-tempo na leitura. A leitura seria a quarta dimensão, o momento em que o texto é enunciado no espaço-tempo e, portanto, um tempo relativo, um espaço-tempo transicional no qual

[...]contextos, mundos, se encontram, chocam ou equivocam, em que [...] a continuidade espaço-temporal dá lugar à contiguidade, e cuja dimensão temporal chamei de estoricidade ou temporalidade originária, em que os tempos e as temporalidades estão se rearranjando, se refazendo a partir do seu encontro com o presente (NODARI, 2017, p. 12).

Blanchot disse que a atividade artística possibilita "exilar-se das dificuldades do tempo e do trabalho no tempo sem renunciar, porém, ao conforto do mundo" (BLANCHOT, 1987, p. 46-47). Tomando a leitura como atividade artística, ler seria entrar em outro espaço-tempo cujo ponto de coordenadas é o texto. Ler implica dilatar ou contrair o tempo, experimentar o tempo em relação ao texto, assim, o tempo do leitor é relativo: um tempo durante a leitura, outro fora, no cotidiano. Quando lemos, pausamos o cotidiano e entramos no texto para viver outra vida em outro tempo, com outro ritmo, em uma realidade oblíqua.

Dessa forma, a leitura coloca um quarto sujeito em jogo: o leitor. De fato, só o leitor pode tentar, embora consciente de que nunca esgotará a obra, escrever/falar a última palavra - não que o sentido escape para outro sentido, como que sempre postergado, mas escapa "no outro de todos os sentidos" (BLANCHOT, 1987, p. 265).

O Autor não apenas precisa criar Ângela para se constituir, mas, ao escrever, precisa inscrever um leitor - "[...] esse alguém que tem reunidos num mesmo campo todos os 
traços que constituem o escrito" (BARTHES, 2004, p. 64) -, uma posição -leitor no texto que mostra que o texto demanda ser lido.

O Autor diz desejar esquecer o leitor, mas não pode, porque o leitor, enquanto posição ficcional, é o sujeito que possibilita a existência do texto como "possibilidade de uma dialética" (BARTHES, 1987, p. 9). O Autor criou Ângela para salvar a vida de alguém, contudo, ele (se) (a) escreve para ser lido, pois o livro - e, consequentemente, ele - só ganha existência pelo leitor, a ponto de se dirigir ao leitor: "Quem és tu que me lês? És o meu segredo ou sou eu o teu segredo?" (LISPECTOR, 1978, p. 81). A escrita existe porque há a leitura (e vice-versa). Escrevemos para que alguém leia.

Parafraseando a frase "escrever é tantas vezes lembrar-se do que nunca existiu" (LISPECTOR, 1980, p. 42), já que "na leitura pensamos os pensamentos de um outro" (ISER, 1996, p. 41), Nodari diz que "ler é, tantas outras, lembrar-se do que nunca se escreveu" (NODARI, 2017, p. 15), pois, como disse Barthes, o leitor não decodifica nem decifra, mas sobrecodifica e cria o texto. Considerando que toda leitura, como a enunciação, é única - até mesmo a releitura -, um novo texto é escrito a cada nova leitura. E a cada texto criado, cria-se um novo mundo: o mundo-de-um-sujeito.

Ao ser inscrito no texto, o leitor não precisa da pessoa do outro, mas do seu espaço dentro do texto (BARTHES, 1987), pois o leitor é esse sujeito que transita por todas as perspectivas presentes no texto e preenche os espaços vazios e indeterminados (ISER, 1996). Ele preenche o eu enunciado pelo Autor e por Ângela e volta ao Autor e de novo à Ângela, e assim até o final, atravessando os silêncios e as entrelinhas. De fato, Ângela e o Autor só podem conversar, só têm o silêncio cortado no monólogo-diálogo através do leitor, pois é este que preenche as entrelinhas da conversa entre os dois e os locais indeterminados da cena-jogo-leitura, pois como disse Clarice: "Mas já que se há de 
escrever, que ao menos não se esmaguem com as palavras as entrelinhas" (LISPECTOR, 1980, p. 25). As entrelinhas são escritas pelo leitor.

O leitor é, assim, o quarto sujeito que preenche o eu da enunciação literária, que performa o outro e se configura como travessia. Ele é o vértice do texto (ISER, 1996, v. 2, p. 15). Em vista disso, analisemos (2):

Figura 2 - Sujeito leitor

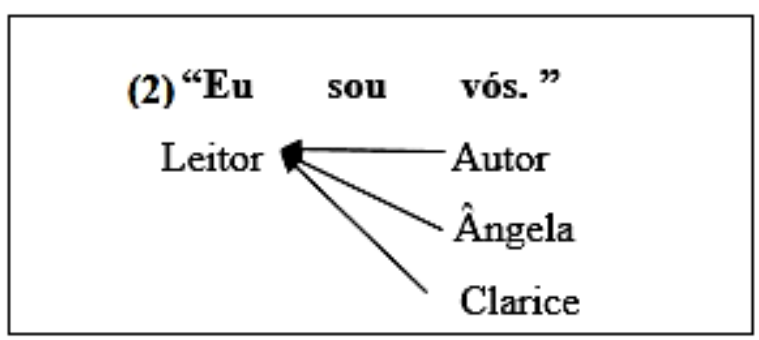

(LISPECTOR, 1978, p. 164)

Esse eu pode ser preenchido por Ângela, Autor, Clarice e pelo leitor. Este, ao ocupar o eu toda vez que aparece, é vós, isto é, os demais, juntando todas as perspectivas do texto. Ele é o eu do "eu te respiro-me", mas também o te. Ainda, considerando a relação de homofonia entre o pronome pessoal "vós" e o substantivo "voz", podemos dizer que o "eu" é vós e também voz, abertura de um espaço de fala - a vez e a voz da enunciação.

Dessa forma, a leitura é o entre-lugar da voz de muitos, e o livro é uma equivocidade, pois é sempre a mesma voz, embora sempre diferente (DELEUZE; GUATTARI, 1995). Com isso, podemos recuperar a consideração de Blanchot (1987, p. 193) de que "ler seria, pois, não escrever de novo o livro, mas fazer com que o livro se escreva ou seja escrito [...] sem ninguém que o escreva", presentificando-o, já que o texto não existe por si só, o leitor "ativa a interação pré-estruturada das frases" (ISER, 1996, p. 15). Nenhuma pessoa disse a frase, a voz da frase é a escrita. A multiplicidade de textos no texto se reúne no leitor, que 
tem, dentro do texto, posição fictício-implícita. Sem abandonar lugar extratextual e sem se confundir com ela, essa posição é encarnada, no ato da leitura, pelo leitor de carne e osso, que é um sujeito formado pela combinação de elementos sócio-históricos e biográficos que luta corpo a corpo com o texto para atravessá-lo e, nessa luta, obliqua-se, porque a palavra é a queda do ego (BARTHES, 1987). Daí a existência de diversos textos: cada leitor lê um texto.

Propomos um esquema matrioskal - imagem já recuperada por Homem (2011) acerca de $A$ hora da estrela - para ilustrar as transições da subjetividade no texto (Figura 1); aproximação produtiva porque, como a boneca, um sujeito está dentro do outro e de si, (alter)ocupando(-se) as posições de sujeito e objeto:

Figura 3 - Esquema matrioskal

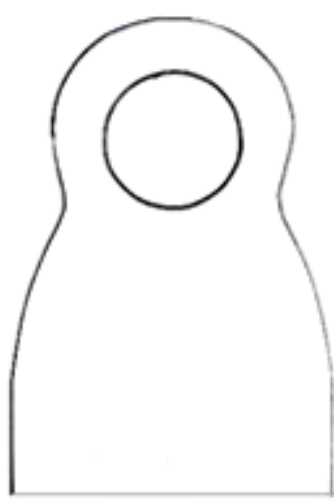

LEITOR

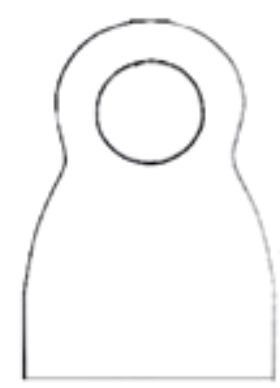

CLARICE LISPECTOR (escritora empirica)

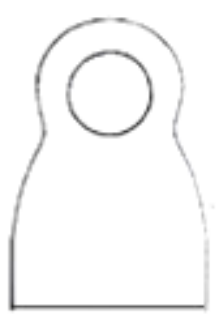

NARRADOR

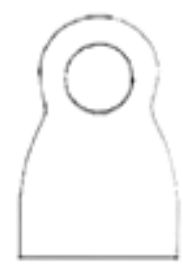

AUTOR

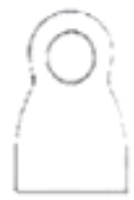

ANGELA LEITOR

Fonte: Da autora

Assim como as matrioskas são todas iguais, mas têm tamanhos diferentes, os sujeitos envolvidos no texto são iguais em sua diferença, pois todos podem ocupar a mesma posição dentro do eu, concomitante e intercambiavelmente. Assim, cada sujeito abre um monólogo-a- $\infty$. Clarice, enquanto escritora, desdobra-se em narrador, Autor e 
Ângela, e também inscreve o leitor. O narrador é desdobramento de Clarice e se desdobra em Autor, Ângela e leitor implícito. Ângela é desdobramento de todos os supracitados e, na posição de autora de seu livro, desdobra-se no leitor implícito que a lerá e redobra todos os que se desdobraram nela. Daí o texto como uma equivocidade matrioskal (Figura 4):

Figura 4-Equivocidade matrioskal

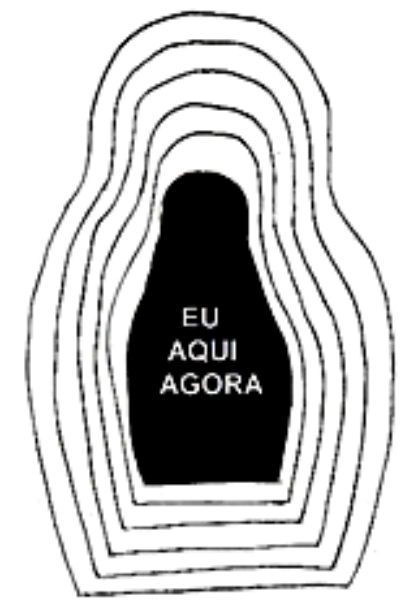

Fonte: Da autora

O leitor é a maior boneca por se configurar como a contraparte da escrita, presentificando o texto na leitura - Clarice só é Clarice na interlocução com o leitor, pois depende desse para existir, assim como esse depende de Clarice para experimentar outros modos de existência. Ao ler, o leitor se despersonaliza para experienciar a multiplicidade subjetiva proposta pelo texto. O leitor é também o vazio - a sombra do texto - que preenche o interior da menor boneca, pois é uma posição textual que une as perspectivas de todos os sujeitos. Dessa forma, o leitor ocupa essas duas posições ao se dividir na leitura, enquanto função leitor e como sujeito "real" que contrapõe a Clarice empírica e que realiza a leitura de fato. Muitos efeitos do texto se dão a partir do jogo 
que ele mobiliza ao entrar em cena nessas duas posições - um leitor implícito e um leitor empírico (ISER, 1996, v. 2).

Chegando ao fim do texto, o leitor desperta, des(alter)ocupa sua posição e volta à realidade com "a sensação de sairmos transformados da leitura, embora nada mude 'de fato'" (NODARI, 2017, p. 16). Para Iser (1996, v. 2, p. 80), isso ocorre porque "é o próprio leitor que está sendo construído", de modo que a leitura mostra como o sujeito não é algo dado, mas construído, dando-nos a oportunidade de nos formularmos pela palavra e pelo pensamento incorporados no texto que escrevemos enquanto lemos. Por fim, SV é uma espécie de testemunho da criação de Ângela, mas também podemos dizer que o livro é o espelho-testemunho da (re)criação de nosso mundo e de nós mesmos por meio dos egos experimentais clariceanos e da própria Clarice.

\section{Referências}

BAKHTIN, Mikhail. Estética da criação verbal. São Paulo: Martins Fontes, 1997.

BARTHES, Roland. O prazer do texto. São Paulo: Perspectiva, 1987. . O rumor da língua. São Paulo: Martins Fontes, 2004.

BENVENISTE, Émile. Problemas de linguística geral I. Campinas, SP: Pontes, 1991. Problemas de linguística geral II. Campinas, SP: Pontes, 1989.

BERGSON, Henri. Duração e simultaneidade. São Paulo: Martins Fontes, 2006.

BLANCHOT, Maurice. O espaço literário. Rio de Janeiro: Rocco, 1987.

DELEUZE, Gilles; GUATTARI, Félix. Mil Platôs - capitalismo e esquizofrenia. Rio de Janeiro: Editora 34, 1995. 
FRIAS, Joana M. Um sopro de vida de Clarice Lispector: a auto-destruição criadora do sujeito moderno. Revista da Faculdade de Leiras "Línguas e Literaturas". Porto, XV, 1998, p. $121-147$.

HOMEM, Maria L. No limiar do silêncio e da letra: traços da autoria em Clarice Lispector. São Paulo, 2011. 205p. Tese (Doutorado em Literatura). Universidade de São Paulo. ISER, Wolfgang. O ato da leitura. v. 1-2. São Paulo: Editora 34, 1996.

LISPECTOR, Clarice. Água viva. Rio de Janeiro: Rocco, 1998.

. A paixão segundo G.H. Rio de Janeiro: Rocco, 2009. . Para não esquecer. São Paulo: Círculo do livro, 1980. . Um sopro de vida. Rio de Janeiro: Círculo do Livro, 1978.

NODARI, Alexandre. Eu, pronome oblíquo. Tradução em Revista. Rio de Janeiro: PUC/RIO, v. 19,2015 a, p. $18-31$

A vida oblíqua: o hetairismo ontológico segundo G.H. O Eixo e a Roda: Revista de Literatura Brasileira. Belo Horizonte: FL-UFMG, v. 24, 2015b, p. 139-154.

Alterocupar-se: obliquação e transicionalidade ontológica. Disponível em:

<https://www.academia.edu/34149784/Alterocupar-

se_obliqua\%C3\%A7\%C3\%A3o_e_transicionalidade_ontol\%C3\%B3gica>. Acesso em: 7 dez. 2017 (2017). p. 1-21.

PENNA, João C. O nu de Clarice Lispector. Alea: Estudos Neolatinos. Rio de Janeiro: FLUFRJ, v. 12, n. 1, 2010, p. 68-96.

Recebido em 16 de março de 2018.

Aceito em 5 de maio de 2018. 